ANKIT BANSAL, Ph.D. Candidate ${ }^{1}$

(Corresponding author)

E-mail: ankitbansal596@gmail.com

TRIPTA GOYAL, Ph.D. ${ }^{1}$

E-mail: triptagoyal@pec.ac.in

UMESH SHARMA, Ph.D. ${ }^{1}$

E-mail: umeshsharma@pec.ac.in

${ }^{1}$ Civil Engineering Department

Punjab Engineering College

Chandigarh, 160012, India
Traffic Engineering

Preliminary Communication

Submitted: 20 June 2019

Accepted: 4 Oct. 2019

\title{
MODELLING THE PEDESTRIAN SPEED AT SIGNALISED INTERSECTION CROSSWALKS FOR HETEROGENEOUS TRAFFIC CONDITIONS
}

\section{ABSTRACT}

Pedestrian crossing speed is the key element in the design of pedestrian facilities. It depends on various attributes related to road, traffic and pedestrians. In this paper, an attempt has been made to explore the variation, examine the influencing factors and formulate a model for the pedestrian crossing speed at signalised intersection crosswalks. The data have been collected using video graphic technique at 16 signalised crosswalks of the Chandigarh city. The findings reveal that a 15th percentile crossing speed (1.11-1.31 $\mathrm{m} / \mathrm{s}$ ) exceeds the design crossing speed of $0.95 \mathrm{~m} / \mathrm{s}$. It is also higher than the crossing speed of $1.2 \mathrm{~m} / \mathrm{s}$, usually being prescribed and adopted in the developed countries. The statistical analysis indicates no significant difference in the percentile crossing speeds between males and females. However, the variation exists among different age groups, group sizes, and crossing patterns. The correlation analysis depicts that the pedestrian crossing speed has significant negative correlation with the crosswalk width, the crosswalk length, the width of the pedestrian island, the classification of road, average traffic flow and average pedestrian delay, whereas the availability of separate bicycle paths at intersections is positively correlated. Furthermore, the stepwise regression model with 70.1 percent accuracy reveals that the crosswalk width, the width of the pedestrian island and the average pedestrian delay play a predominant role in determining the pedestrian crossing speed. The authors propose the usage of the developed model for setting out the standards for the appropriate design crossing speed for different crosswalks having similar geometric and traffic conditions as that of the study area.

\section{KEY WORDS}

pedestrians; crossing speed; crosswalk; intersection; percentile;

\section{INTRODUCTION}

Pedestrian safety is the key concern while crossing at signalised intersections in the developing nations. The pedestrians face a number of conflicts with the vehicular traffic and experience maximum delays at the intersections [1]. This leads to the pedestrians' erratic crossing behaviour which results in the rise in the number of accidents. With the increase in the number of pedestrian accidents the concern of pedestrian safety has become essential [2]. Therefore, there is need for proper designing of signalised intersection crosswalks. The pedestrian crossing speed is a vital factor for the effective implementation of safety measures and designing of the crosswalks at intersections. Hence, it is essential to have adequate knowledge of the pedestrian crossing speed under heterogeneous crossing conditions. The design manuals such as the Traffic Engineering Handbook [3] propose a speed of 0.91-0.98 m/s and the Highway Capacity Manual [4] suggests $1.2 \mathrm{~m} / \mathrm{s}$ as the appropriate speed for the design of pedestrian facilities (if the population of elderly people accounts for less than 20 percent of the total population). The Manual of Uniform Traffic Control Devices for Streets and Highways (MUTCD) [5] also advises a standard value of $1.21 \mathrm{~m} / \mathrm{s}$ for kerb-to-kerb crossing. The average crossing speed ranges between $0.75-1.21 \mathrm{~m} / \mathrm{s}$ on the basis of heterogeneous mix of pedestrians (age and gender). The Indian Roads Congress (IRC) suggests a crossing speed of $0.98 \mathrm{~m} / \mathrm{s}$ for educational and recreational areas. The $15^{\text {th }}$ percentile speed of $0.95 \mathrm{~m} / \mathrm{s}$ should be used for the design 
of pedestrian crossing facilities. If elder pedestrians account for a greater proportion, the crossing speed of $0.79 \mathrm{~m} / \mathrm{s}$ should be used [6].

The literature indicates that the variation in the pedestrian crossing speed limits (as prescribed by different manuals) is mainly a consequence of the difference in location, geometric site conditions and pedestrian behavioural characteristics. Numerous factors for instance, type of crosswalk, pedestrian socio-demographics (age, gender and group size) and flow characteristics (flow and conflicting flow) significantly affect the crossing speed [7-10]. Lam and Cheung [11] investigated the pedestrian flow behaviour at several crosswalks in Hong Kong and found that the pedestrians usually walk faster at crosswalks without a midblock. Similarly, the study conducted at signalised and non-signalised crosswalks in Malaysia by Goh et al. [12] inferred that pedestrians at non-signalised crosswalks have considerably faster crossing speed than at signalised crosswalks. Studies carried out at different locations reveal a variation in the crossing speed of the adults and elder pedestrians. The studies undertaken in the UK stated an average crossing speed between 1.32-1.72 m/s for younger pedestrians and between 1.11-1.16 m/s for elderly pedestrians [13-16]. In the United States, the variation in the crossing speeds of the elderly people ranges between 0.97-1.34 m/s with the margin of +0.5 percent [17-19]. In Sweden, elder pedestrians usually walk at speeds lower than $0.7 \mathrm{~m} / \mathrm{s}$ [20]. The crossing speed in the Netherlands is found to be $1.24 \mathrm{~m} / \mathrm{s}$ for elder pedestrians and 1.5 $\mathrm{m} / \mathrm{s}$ for the younger ones [21]. Studies undertaken in India also reveal that young pedestrians cross the street at a faster pace (1.24-1.42 m/s) in comparison to middle-aged (1.15-1.24 m/s) and elder pedestrians (0.98-1.23 m/s) [22-24].

Likewise, the effect of gender on the crossing speed has been also explored by various authors. Tanaboriboon and Guyano [25] observed that men walk faster than women by $0.6 \mathrm{~m} / \mathrm{s}$ at signalised intersections in Bangkok. Similarly, Tarawneh [26] conducted a study in Jordan and found that the male crossing speed $(1.35 \mathrm{~m} / \mathrm{s})$ is on the higher side as compared to the female counterpart $(1.33 \mathrm{~m} / \mathrm{s})$ and the speed also depends on the crosswalk width. Subramanyam and Prasanna [27] also found similar results in India and revealed that male crossing speed exceeds the female crossing speed by $0.17 \mathrm{~m} / \mathrm{s}$. Further, DiPietro and King [28] observed that the $15^{\text {th }}$ percentile speed is 0.76 $\mathrm{m} / \mathrm{s}$ for a single pedestrian, $0.67 \mathrm{~m} / \mathrm{s}$ for pedestrians in a pair and $0.61 \mathrm{~m} / \mathrm{s}$ for more than two pedestrians. Gates et al. [19] also found that the pedestrian speed for crossing in groups is lower than crossing individually $(1.32 \mathrm{~m} / \mathrm{s}$ as opposed to $1.44 \mathrm{~m} / \mathrm{s})$. Hatfield and Murphy [29] revealed that the mobile phones do not affect the crossing speed of pedestrians but increase the tendency of hazardous road crossing behaviour.
Goh and Lam [30] pointed out that the pedestrians crossing in oblique fashion with two-stage crossing have lower speed as compared to one-stage crossing. Moreover, Rastogi et al. [31] deduced that traffic volume, width of road and urban area size have positive influence on the crossing speed. The preceding discussion reveals that the socio-demographic factors (such as gender, age group size), geometric characteristics (such as road width, road classification) and flow conditions are the significant factors influencing the crossing speed of pedestrians at signalised crosswalks. It is evident from Table 1 that over a period of time, the average pedestrian crossing speed has increased (1.24-1.43 m/s) due to the improvement in traffic conditions and infrastructure facilities [32-34]. Therefore, the present study aims to determine the factors that affect the crossing speed and to model the pedestrian crossing speed for the selected signalised intersection crosswalks in the Chandigarh city under heterogeneous traffic conditions.

\section{METHODOLOGY}

The present study was carried out in one of the well-planned cities of India - Chandigarh. The selected sites varied in terms of traffic volume, numbers of lanes, nature of land-use and other geometric features. The crosswalks were either four/six-lane divided or three-lane undivided carriageways. The Chandigarh city has the best urban planning and modern architecture. It also has the largest number of vehicles per capita in India, due to which non-motorised users face inconvenience in manoeuvrability on the roads especially at the time of crossing at intersections. The statistics show that during the past five years, road accidents claimed 664 lives of which 213 were pedestrians, which accounts for 32.07 percent of the total deaths [39]. This indicates a severe mistake of ignoring the non-motorised traffic in the city road designs. Hence, the data were collected at 16 signalised crosswalks (C1-C16) in Chandigarh city.

Videographic technique was used to gather the pedestrian flow data during the morning peak hour, i.e. between 9:00 a.m. to 10:00 a.m. A total of 994 samples were collected at signalised crosswalks which were further classified into different genders and age groups (less than 18, 19 to 29,30 to 44,45 to 59 , equal to and above 60). The crossing speed of the pedestrians was computed based on the time taken by a pedestrian to cross the road between the kerb and the median. From the observed data, the average crossing speed was estimated under varying pedestrian flow conditions. The cumulative S-shaped frequency curves were used to find the percentile speeds at different crosswalks among the various genders, age groups and group sizes. The pedestrian flow, crossing time and delay, vehicular flow and speed were also 
Bansal A, Goyal T, Sharma U. Modelling the Pedestrian Speed at Signalised Intersection Crosswalks for Heterogeneous Traffic Conditions

Table 1 - Comparison of pedestrian crossing speeds among different countries on the basis of socio-demographics

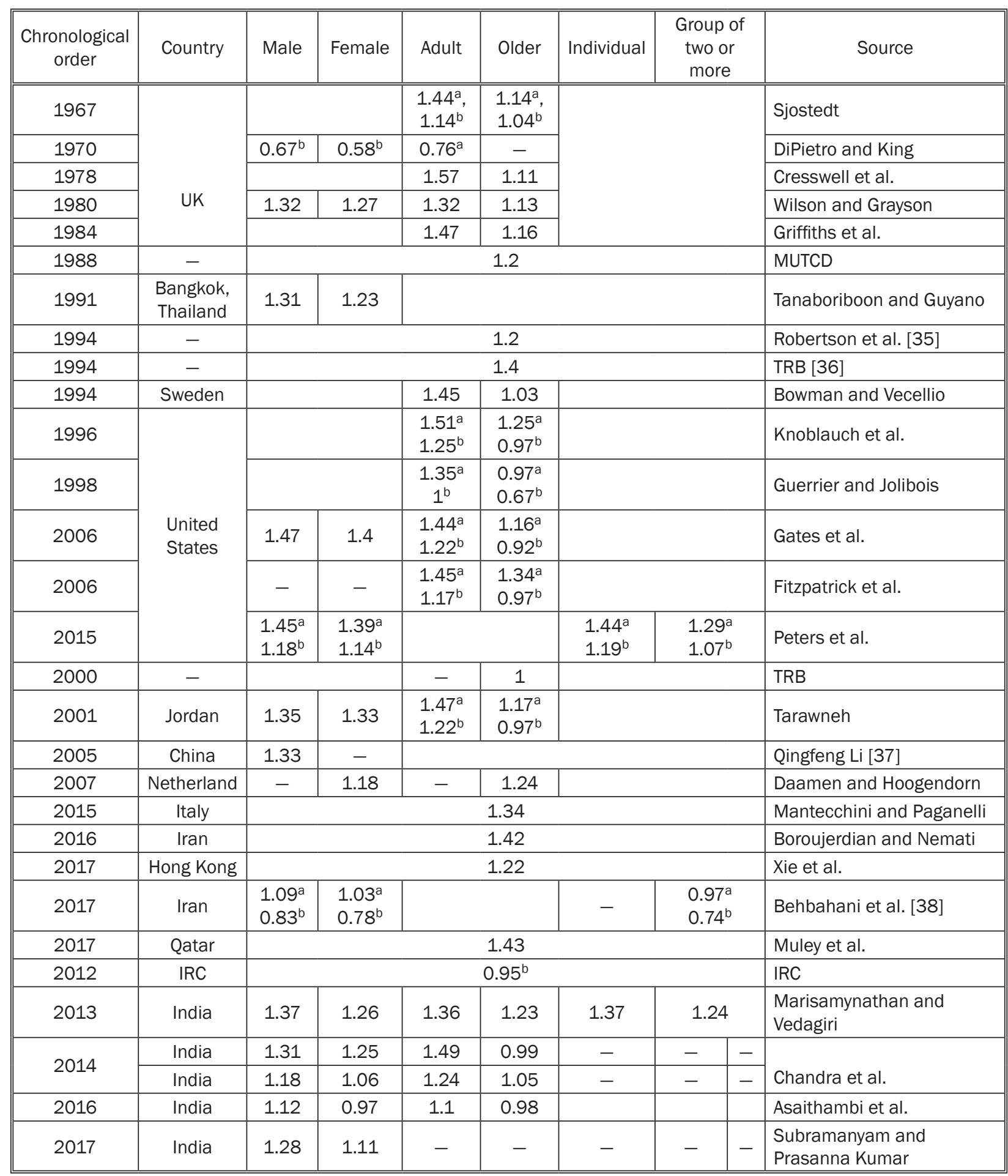

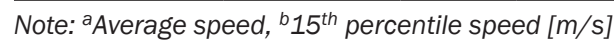

deduced from the videography. The details of the geometric features of the crosswalks were observed manually. The geometric features, pedestrian flow and traffic flow characteristics are depicted in Table 2.

A one-way analysis of variance (ANOVA)/F-test was applied to check the significance of the social factors or demographic factors on the pedestrian crossing speed. Thereafter, the correlation analysis was performed to check whether the factors (geometric and operational) undertaken in the present study have any relation with the crossing speed. The Pearson bivariate correlation analysis was carried out for continuous factors, Eta-squared analysis for nominal variables and Kruskal's Gamma analysis for ordinal variables. Multi-collinearity diagnostics test was also run for examining the VIF (Variance Inflation factor) 
Table 2 - Geometric features, operational and flow characteristics of the study area

\begin{tabular}{|c|c|c|c|c|c|c|c|c|c|c|c|c|c|c|c|c|}
\hline Site & $\begin{array}{c}\mathrm{C} \\
{[\mathrm{s}]} \\
\end{array}$ & $\begin{array}{c}G \\
{[\mathrm{~s}]}\end{array}$ & $\begin{array}{c}W \\
{[\mathrm{~m}]}\end{array}$ & $\begin{array}{c}\mathrm{L} \\
{[\mathrm{m}]}\end{array}$ & $\begin{array}{l}\text { Wp } \\
{[\mathrm{m}]}\end{array}$ & VC & $\mathrm{CR}$ & SBP & GR & CS & LU & $\begin{array}{c}\mathrm{P} \\
\text { [ped/h] }\end{array}$ & $\begin{array}{c}\mathrm{T} \\
{[\mathrm{PCU} / \mathrm{h}]} \\
\end{array}$ & $\begin{array}{c}\mathrm{V} \\
{[\mathrm{km} / \mathrm{h}]}\end{array}$ & $\begin{array}{l}\mathrm{Ct} \\
{[\mathrm{s}]}\end{array}$ & $\begin{array}{c}D \\
{[s]}\end{array}$ \\
\hline C-1 & 112 & 30 & 3.2 & 35.0 & 11.0 & 3 & 2 & 2 & 1 & 2 & 2 & 131 & 3,868 & 41.3 & 25 & 5.40 \\
\hline $\mathrm{C}-2$ & 112 & 40 & 3.0 & 27.0 & 8.6 & 3 & 1 & 2 & 0 & 2 & 2 & 43 & 3,195 & 43.9 & 18 & 7.35 \\
\hline C-3 & 112 & 40 & 3.2 & 27.8 & 14.5 & 3 & 1 & 2 & 0 & 2 & 2 & 191 & 3,086 & 42.8 & 19 & 7.46 \\
\hline C-4 & 112 & 30 & 3.2 & 35.1 & 9.1 & 3 & 2 & 2 & 1 & 2 & 2 & 96 & 4,071 & 43.6 & 25 & 7.66 \\
\hline C-5 & 135 & 69 & 2.9 & 34.0 & 6.6 & 3 & 2 & 2 & 1 & 2 & 2 & 35 & 3,879 & 42.8 & 23 & 7.94 \\
\hline C-6 & 135 & 37 & 2.9 & 26.1 & 8.1 & 2 & 1 & 1 & 0 & 1 & 2 & 34 & 3,094 & 43.9 & 17 & 9.58 \\
\hline C-7 & 135 & 33 & 3.0 & 26.7 & 6.2 & 2 & 1 & 1 & 0 & 1 & 2 & 36 & 2,099 & 44.6 & 18 & 9.33 \\
\hline C-8 & 135 & 47 & 3.1 & 33.2 & 7.4 & 3 & 2 & 2 & 1 & 2 & 2 & 36 & 3,432 & 42.1 & 23 & 8.25 \\
\hline C-9 & 146 & 62 & 3.2 & 29.9 & 7.5 & 3 & 2 & 2 & 1 & 2 & 2 & 102 & 3,422 & 42.6 & 22 & 11.6 \\
\hline C-10 & 146 & 57 & 3.0 & 22.7 & 8.6 & 0 & 1 & 1 & 0 & 0 & 2 & 58 & 2,966 & 43.1 & 15 & 7.56 \\
\hline C-11 & 146 & 40 & 2.9 & 21.4 & 6.5 & 1 & 1 & 1 & 0 & 1 & 2 & 48 & 2,877 & 46.7 & 15 & 9.99 \\
\hline C-12 & 146 & 42 & 3.0 & 30.8 & 7.0 & 3 & 2 & 2 & 1 & 2 & 2 & 99 & 3,613 & 44.9 & 20 & 6.20 \\
\hline C-13 & 125 & 36 & 3.0 & 21.8 & 20.0 & 2 & 2 & 0 & 1 & 1 & 0 & 29 & 3,445 & 41.3 & 15 & 7.31 \\
\hline C-14 & 125 & 36 & 3.1 & 15.1 & 15.2 & 0 & 1 & 0 & 0 & 0 & 2 & 18 & 3,050 & 42.1 & 12 & 12.9 \\
\hline C-15 & 125 & 36 & 2.9 & 12.4 & 25.0 & 0 & 0 & 0 & 0 & 0 & 0 & 20 & 3,069 & 40.6 & 10 & 11.6 \\
\hline C-16 & 125 & 36 & 3.1 & 22.3 & 18.2 & 2 & 2 & 0 & 1 & 1 & 2 & 38 & 3,280 & 41.3 & 17 & 9.11 \\
\hline
\end{tabular}

Note: $C$ - Cycle length, $G$ - Green time for pedestrians, $W$ - Width of crosswalk, $L$ - Length of crosswalk, Wp - Width of pedestrian islands, VC - Visibility of cross markings (Not visible - 0, Slightly visible - 1, Moderately visible - 2, Highly visible - 3), CR - Classification of road (Three-lane undivided - 0, Four-lane divided - 1, Six-lane divided - 2), SBP - Separate bicycle path for crossing (0 - Not available, 1 - Semi operational, 2- Fully operational), GR - Presence of guard rails (No - 0, Yes - 1), CS - Crosswalk Surface Condition (Poor - 0, Fair - 1, Good 2), LU - Nature of land use (Commercial - 0, Educational - 1, Mixed - 2, Recreational/Shopping - 3, Residential - 4), P - Average pedestrian flow, $T$ - Average traffic flow, $V$ - Average traffic speed, Ct - Average crossing time, D - Average pedestrian delay

values to check the collinearity among the independent variables. Dummy variables were assigned to the categorical variables for formulating the model using stepwise regression technique. The model validity was checked using the goodness-of-fit tests.

\section{PARAMETRIC ANALYSIS OF THE CROSSING SPEED}

The $15^{\text {th }}$ percentile speed is the design speed for deciding on the pedestrian signal timings for pedestrians to cross safely. The $15^{\text {th }}$ percentile speeds are found to vary between 1.11-1.31 m/s for all crosswalk locations, which is consistent with the standard value of $1.2 \mathrm{~m} / \mathrm{s}$ as suggested by different manuals (HCM 2000, FHWA 2003) [4, 40], but higher than that prescribed by IRC $(0.95 \mathrm{~m} / \mathrm{s})$ [6]. The $50^{\text {th }}$ percentile speed fluctuates between 1.29-1.56 m/s which represents the speed at which half of the pedestrians are below and half of the pedestrians are above. The $85^{\text {th }}$ percentile speed ranges between 1.54-1.85 m/s which indicates the maximum speed at which pedestrians could cross the road so as to avoid accidents. These values are higher than the values recommended by researchers in other developing countries with similar crosswalk conditions. The variation of the speed percentiles is presented in Figure 1. The lowest percentile speeds are observed at C-9, C-14 and C-16 locations, whereas the maximum percentile speeds are found at C-2, C- 6 and C-12 locations. This may be due to the difference in the crosswalk characteristics or flow conditions which is evident from Table 2. The delays experienced by various pedestrians are maximum at C-9, C-14 and C-15 crosswalk locations due to which the crossing speed gets reduced.

\subsection{Pedestrian socio-demographic features (gender, age group, group size)}

The results of the percentile crossing speed (crosswalk-wise) with respect to gender, age-group and group size are presented in Table 3. Table 3 depicts that the males and females speed do not vary significantly as indicated by F-Value (< F-Critical) $(F=1.392$ $<2.389, p=0.289$ ). The average crossing speed of male and female pedestrians is 1.48 and $1.47 \mathrm{~m} / \mathrm{s}$, respectively which indicate that males walk faster than females by trivial margin of $0.01 \mathrm{~m} / \mathrm{s}$. It is also noticed that $15^{\text {th }}$ and $85^{\text {th }}$ percentile speeds of both males and females are on the higher side as compared to the speed observed in other countries $(0.83 \mathrm{~m} / \mathrm{s}$ and $1.25 \mathrm{~m} / \mathrm{s}$ in Iran; $1.18 \mathrm{~m} / \mathrm{s}$ and $1.54 \mathrm{~m} / \mathrm{s}$ in the United States) [9, 39]. Another important observation is that the crossing speed of pedestrians at all signalised crosswalk locations show significant variation $(p=0.045)$ and decrease with the age of the pedestrians (Table 3). Moreover, it is found that about 80 percent of the elder pedestrians (above 60 years) and 85 percent of pedestrians in the age group of 


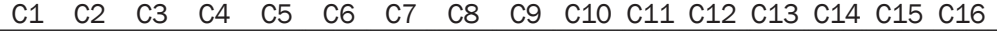

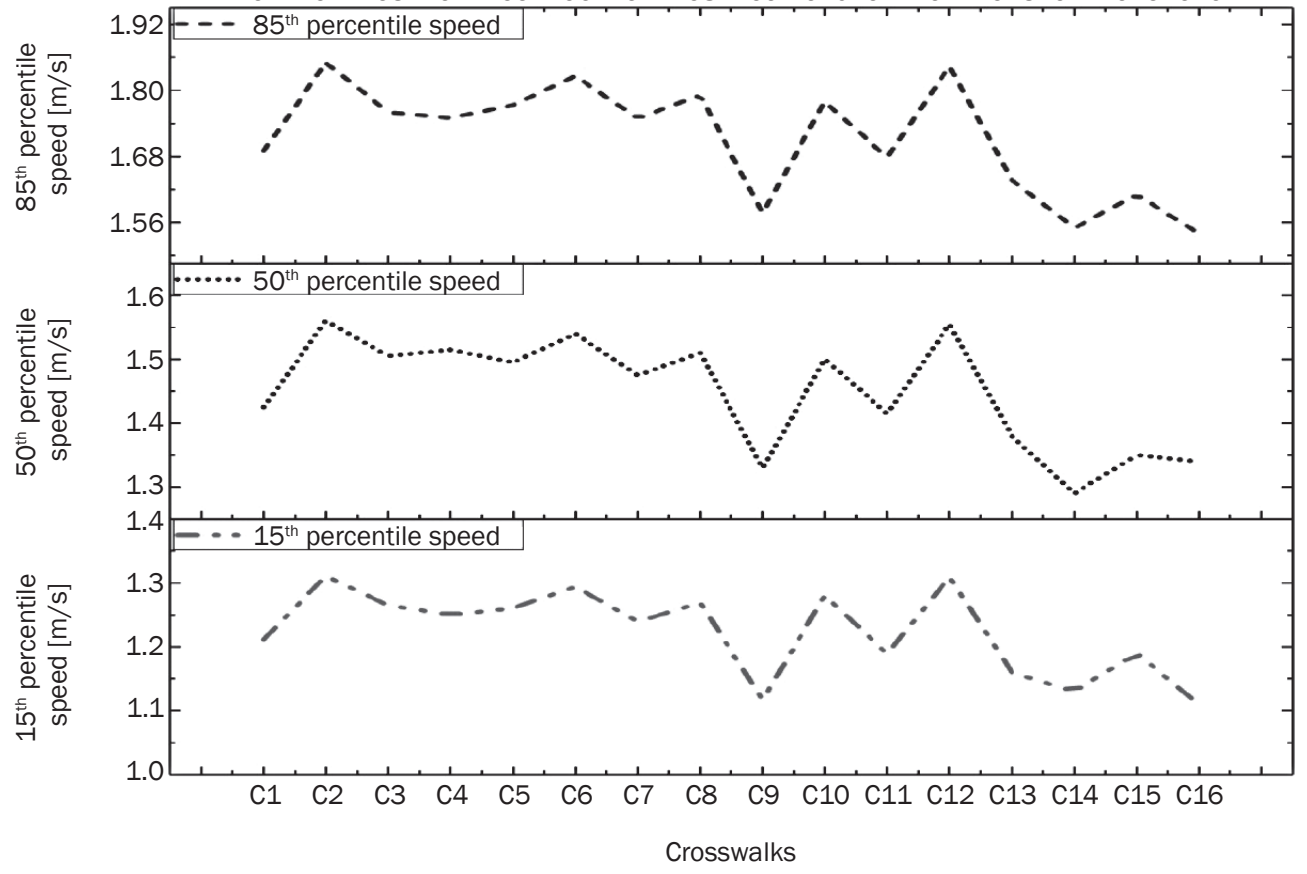

Figure 1 - Variation in percentile speeds across different locations

Table 3 - Statistical significance of variation in crossing speeds

\begin{tabular}{|c|c|c|c|c|c|c|c|c|c|}
\hline \multicolumn{2}{|c|}{ Parameters } & \multirow[t]{2}{*}{$N$} & \multicolumn{3}{|c|}{ Range } & \multirow[t]{2}{*}{$\begin{array}{c}\text { Avg. } \\
\text { crossing } \\
\text { speed }\end{array}$} & \multirow{2}{*}{$\begin{array}{l}F \text {-Ratio } \\
\text { statistic }\end{array}$} & \multirow[t]{2}{*}{$F$-Critical } & \multirow[t]{2}{*}{$p$} \\
\hline & & & $15^{\text {th }}$ & $50^{\text {th }}$ & $85^{\text {th }}$ & & & & \\
\hline \multirow{2}{*}{ Gender } & Male & 650 & $1.06-1.33$ & $1.26-1.58$ & $1.49-1.87$ & 1.48 & \multirow{2}{*}{1.392} & \multirow{2}{*}{2.389} & \multirow{2}{*}{$\begin{array}{c}\text { 0.235, } \\
\text { Not } \\
\text { significant }\end{array}$} \\
\hline & Female & 344 & $1.13-1.31$ & $1.23-1.54$ & $1.46-1.83$ & 1.47 & & & \\
\hline \multirow{5}{*}{ Age group } & $<18$ & 222 & $1.19-1.36$ & $1.26-1.64$ & $1.52-1.86$ & 1.51 & \multirow{5}{*}{3.121} & \multirow{5}{*}{1.652} & \multirow{5}{*}{$\begin{array}{l}0.045^{*}, \\
\text { Significant }\end{array}$} \\
\hline & $18-29$ & 294 & $1.07-1.32$ & $1.27-1.61$ & $1.51-1.87$ & 1.49 & & & \\
\hline & $30-44$ & 301 & $1.05-1.33$ & $1.26-1.58$ & $1.49-1.84$ & 1.47 & & & \\
\hline & $45-59$ & 135 & $0.91-1.25$ & $1.21-1.54$ & $1.48-1.82$ & 1.46 & & & \\
\hline & $\geq 60$ & 42 & $0.89-1.23$ & $1.2-1.5$ & $1.46-1.79$ & 1.39 & & & \\
\hline \multirow{3}{*}{ Group size } & One & 623 & $1.18-1.35$ & $1.29-1.59$ & $1.53-1.79$ & 1.52 & \multirow{3}{*}{2.124} & \multirow{3}{*}{0.954} & \multirow{3}{*}{$\begin{array}{l}\text { 0.032*, } \\
\text { Significant }\end{array}$} \\
\hline & Two & 256 & $1.14-1.32$ & $1.27-1.54$ & $1.49-1.75$ & 1.53 & & & \\
\hline & $\geq$ Three & 115 & $1.15-1.33$ & $1.24-1.52$ & $1.48-1.77$ & 1.52 & & & \\
\hline
\end{tabular}

Note: * Significant, if $p<0.05$

18-45 years have crossing speeds higher than 1.2 $\mathrm{m} / \mathrm{s}$. This may be due to more agility in the young pedestrians and psychological tendency of the elder pedestrians to have minimum interactions with the vehicular traffic while crossing. The $15^{\text {th }}$ percentile speeds of different age groups are almost in coherence with the standard crossing speed of $1.2 \mathrm{~m} / \mathrm{s}$. Correspondingly, the significant difference in the crossing speed exists among various group sizes $(p=0.032)$. The group walking speeds varied from the speed of the individuals. The time difference between the entry of the first pedestrian and the exit of the last pedestrian of the group from the section was used to compute the group speed. The person crossing alone has higher crossing speed than those crossing in pairs or groups. The speed decreases with the increase in the size of the pedestrian group. The $15^{\text {th }}$ percentile speed gets reduced by 25 percent as the group size increases above 3 . The proportion of pedestrians crossing in a group of three and above are below 15 percent; therefore, the design crossing speed should range according to the speed of individuals and crossing in a pair. The observations clearly indicate that the design crossing speed needs to be revised according to the present crosswalk characteristics, geometric features and flow conditions. 


\subsection{Crossing pattern, baggage and mobile use}

Different types of crossing patterns have been observed while using the crosswalk i.e. one-stage and two-stage crossings which could either be perpendicular, oblique, or a combination of both. The proportion of one-stage crossing (59 percent) is found to be greater compared to the two-stage crossing (41 percent). It is observed that the mean value of the crossing speed is higher in the case of one-stage crossing $(1.5 \mathrm{~m} / \mathrm{s})$ as compared to the two-stage crossing $(1.44 \mathrm{~m} / \mathrm{s})$. In case of a two-stage crossing, the pedestrians have to stop at the median for a while which results in an increase in the overall crossing time and reduction of the overall crossing speed.

Another interesting inference is that the pedestrians carrying baggage or using mobile phones (either speaking to someone or texting or surfing over the mobile phone) have a significant effect on the crossing speed. The speed at the time of crossing decreases if the pedestrians are carrying baggage or using mobile phones because this may divert their attention/focus towards either handling the baggage or using the mobile phones (especially texting or surfing), and as a result the crossing speed gets hindered. The mean speeds observed at different locations for pedestrians in case of carrying baggage and using mobile phones are found to be 1.42 and $1.43 \mathrm{~m} / \mathrm{s}$, respectively, which is less than the mean speed observed under normal conditions $(1.48 \mathrm{~m} / \mathrm{s})$.

\subsection{Geometric features, operational and flow characteristics}

Along with the socio-demographic factors discussed in the preceding sections, the crossing speed also depends on the geometric features of the crosswalk such as the crosswalk width, the crosswalk length, the width of pedestrian islands, visibility of the cross-markings, the presence of guard rails, the classification of roads, the signal cycle length and the green time allocated to the pedestrians. In the present study, the correlation analysis (Pearson bivariate correlation analysis for continuous factors, Eta-squared analysis for nominal variables and Kruskal's Gamma analysis for ordinal variables) depicts that a significant correlation has been observed for seven factors only, such as the crosswalk width, the width of pedestrian islands, the crosswalk length, separate bicycle paths for crossing, classification of roads, average traffic flow and average pedestrian delay (Table 4). The effect of each factor on the pedestrian crossing speed has been discussed in the following paragraphs.

The correlation analysis reveals that the pedestrian crossing speed has significant negative correlation with the crosswalk width $(R=-0.499, p=0.048)$ and the width of pedestrian islands $(R=-0.625, p=0.010)$ (Table 4). This signifies the reduction in the crossing speed with the increase in the width of crosswalk and pedestrian island. Extra width of the crosswalk and the pedestrian islands (additional space available) may result in more comfortability to the pedestrians in their

Table 4 - Variation in crossing speed with respect to different attributes/factors

\begin{tabular}{|c|c|c|c|c|c|}
\hline \multirow{2}{*}{ Type } & \multirow{2}{*}{ Attributes/factors } & \multirow{2}{*}{$\begin{array}{l}\text { Nature of } \\
\text { variable }\end{array}$} & \multicolumn{2}{|c|}{ Correlation } & \multirow{2}{*}{ Analysis tool } \\
\hline & & & $R$ & $p$ & \\
\hline \multirow{2}{*}{$\begin{array}{c}\text { Operational } \\
\text { characteristics }\end{array}$} & Cycle length & Continuous & 0.089 & 0.742 & \multirow{5}{*}{$\begin{array}{c}\text { Pearson bivariate } \\
\text { (Continuous / } \\
\text { Interval by interval }^{\star *} \text { ) }\end{array}$} \\
\hline & Green time for pedestrians & Continuous & 0.049 & 0.856 & \\
\hline \multirow{9}{*}{$\begin{array}{l}\text { Geometric } \\
\text { features }\end{array}$} & Crosswalk width & Continuous & -0.499 & $0.048^{*}$ & \\
\hline & Crosswalk length & Continuous & -0.537 & $0.032^{*}$ & \\
\hline & Width of pedestrian islands & Continuous & -0.625 & $0.010^{*}$ & \\
\hline & Nature of land use & Nominal & 0.394 & 0.131 & \multirow{3}{*}{$\begin{array}{c}\text { Eta-squared } \\
\text { (Nominal by interval) }\end{array}$} \\
\hline & Presence of guard rails & Nominal & -0.118 & 0.664 & \\
\hline & Classification of road & Nominal & -0.502 & $0.039^{*}$ & \\
\hline & Visibility of cross markings & Ordinal & 0.343 & 0.193 & \multirow{3}{*}{$\begin{array}{l}\text { Kruskal's Gamma } \\
\text { (Ordinal by interval) }\end{array}$} \\
\hline & Crosswalk surface condition & Ordinal & 0.58 & 0.452 & \\
\hline & Separate bicycle path & Ordinal & 0.604 & $0.013^{*}$ & \\
\hline \multirow{5}{*}{$\begin{array}{c}\text { Flow } \\
\text { characteristics }\end{array}$} & Average pedestrian flow & Continuous & 0.165 & 0.541 & \multirow{5}{*}{ Pearson bivariate } \\
\hline & Average traffic flow & Continuous & -0.544 & $0.028^{*}$ & \\
\hline & Average traffic speed & Continuous & 0.494 & 0.052 & \\
\hline & Average crossing time & Continuous & 0.388 & 0.138 & \\
\hline & Average pedestrian delay & Continuous & -0.584 & $0.017^{*}$ & \\
\hline
\end{tabular}

Note: ${ }^{\star}$ Significant, if $p<0.05,{ }^{* *}$ Crossing speed is also of continuous (interval) nature. 
crossing manoeuvres. This in turn leads to psychological no-haste condition by some of the pedestrians. The best fitted curves in both cases are found to be cubic in nature with the coefficient of determination ( $R$-square) values of 0.412 and 0.513 , respectively. Thus, the crossing speed can be suitably predicted with the help of the crosswalk width and the width of pedestrian islands with 41 percent success rate.

The study was carried out for three types of roads: three-lane undivided, four-lane divided and six-lane divided carriageway. For analysis of crossing speed, the three-lane undivided carriageway is considered same as the four-lane divided carriageway because both carriageways have somewhat similar geometric features and flow characteristics (crosswalk surface condition, separate bicycle path and traffic flow etc.). The variation in the percentile speeds for different classes of roads is shown in Figure 2. It is observed that the $15^{\text {th }}$ percentile speed and $85^{\text {th }}$ percentile speed have higher values for four-lane divided carriageways in comparison to the six-lane divided carriageways $(1.24 \mathrm{~m} / \mathrm{s}$ vs $1.21 \mathrm{~m} / \mathrm{s}$ and $1.73 \mathrm{~m} / \mathrm{s}$ vs $1.7 \mathrm{~m} / \mathrm{s}$ respectively). The correlation analysis results replicate for the length of crosswalk (i.e. moderate negative correlation with the crossing speed) $(R=-0.537, p=0.032)$ (refer to Table 4). It is noted that the average crossing speed is more in case of four-lane divided carriageways as compared to the six-lane divided carriageways. The distance to be covered is more in the latter case which results in increase in time for kerb to kerb crossing. It also increases the probability of pedestrian-vehicular interaction in case of signal non-compliance either by vehicle or pedestrian. However, these results are contradictory to the results obtained by Rastogi et al. while conducting a study at midblock crosswalks in India [31]. Therefore, this also confirms that the crossing speed is also a function of the crosswalk type (signalised, unsignalised or mid-block).

Figure 3 shows the effect of traffic flow on the crossing speed of the pedestrians. The traffic flow (bi-directional) ranges between 2,099-4,071 PCU/hour with the average traffic speed of $42 \mathrm{~km} / \mathrm{h}$. Table 4 indicates that the traffic flow has negative correlation with the crossing speed $(R=0.544, p=0.028)$. However, according to the best fitted curve with $R$-square value 0.4469 predicts that the crossing speed initially increases when the traffic flow is lower ( $<2,750 \mathrm{PCU} /$ hour), and as it increases further, the corresponding crossing speed decreases. The dip in the crossing speed with increase in traffic volume is due to the increase in the number of pedestrian-vehicular interactions while crossing, thus increasing the overall pedestrian crossing time.
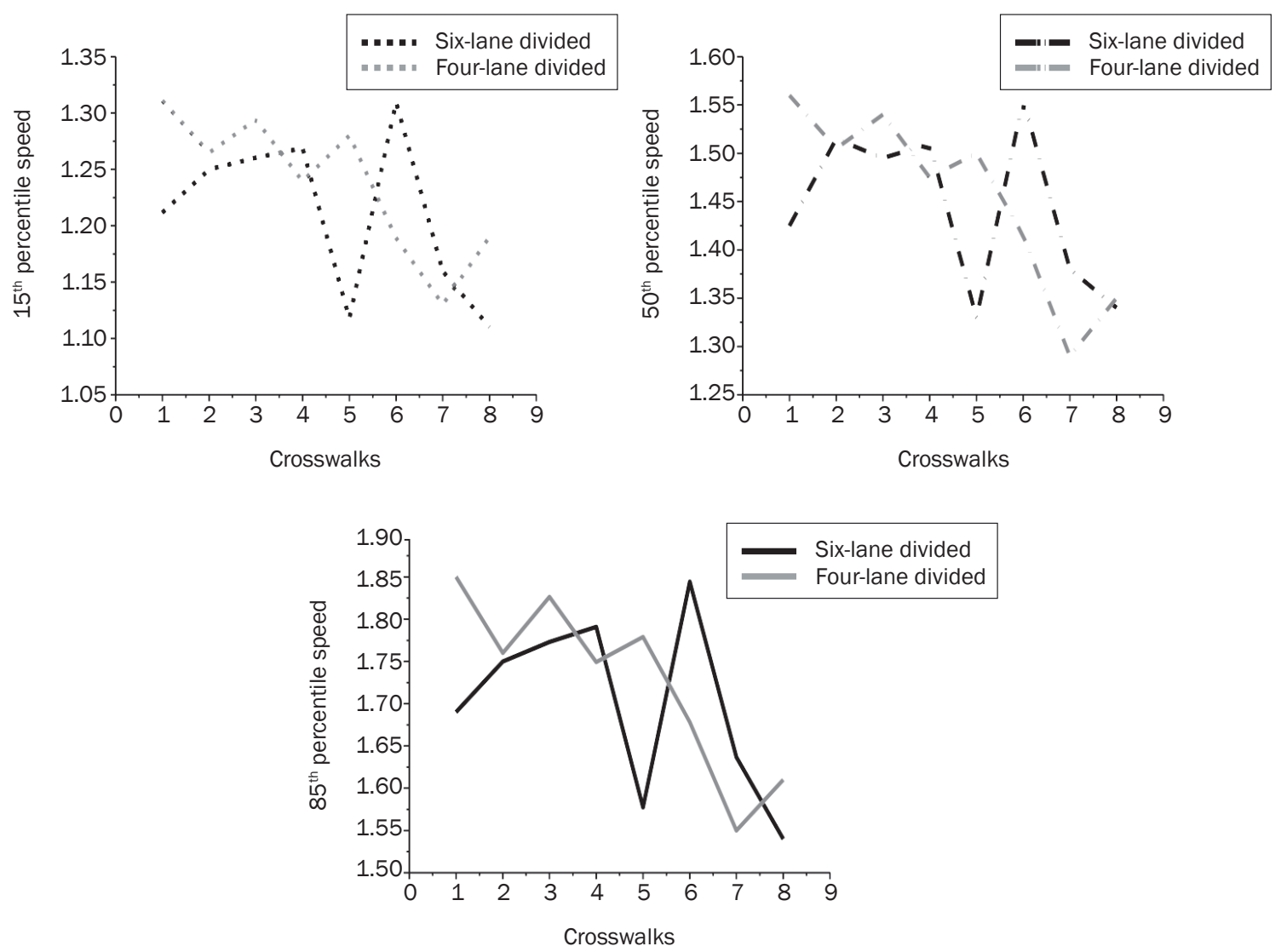

Figure 2 - Variation in percentile speeds for different carriageways 


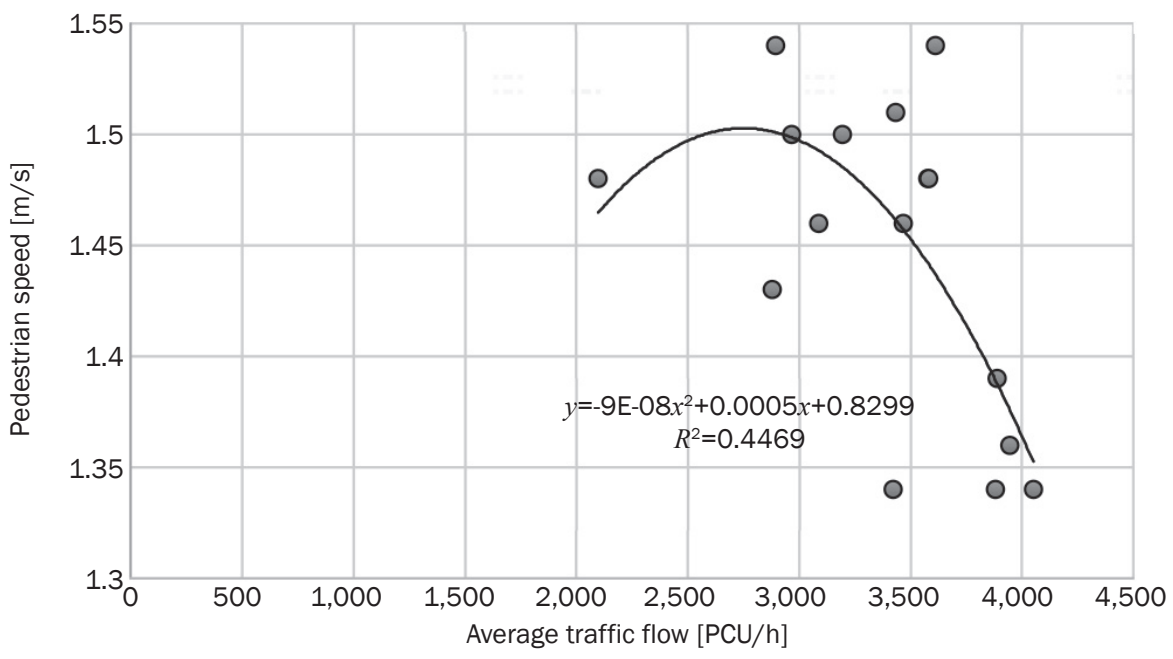

Figure 3 - Variation in crossing speed with traffic volume

Pedestrian delay is also one of the major factors that affect the crossing speed. In the present study, the delay experienced by pedestrians while crossing is only considered for examining its effect on the crossing speed. Table 4 clearly indicates that pedestrian delay has negative correlation with the crossing speed $(R=-0.584, p=0.017)$. However, the relation between the pedestrian delay is not linear. The cubic curve best with 47 percent accuracy rate describes the decrease in the crossing speed with the increase in pedestrian delay.

Nowadays, most of the cities are equipped with the cycle tracks solely for the use of cyclists. Chandigarh city is also equipped with the cycle tracks either running parallel to the main carriageway or at separate locations. For crossings of cyclists at the intersections, separate paths have been provided so as to avoid interaction with the pedestrians while crossing. For the present study, 50 percent of the crosswalks have fully operational separate cyclist crossings, whereas 25 percent of crosswalks are in semi-operational condition (under construction). The rest of 25 percent do not have separate cyclist crossings. The correlation analysis shows that there is positive relation between the pedestrian crossing speed and the availability of separate bicycle paths $(R=0.604, p=0.013)$. The pedestrian crossing speed lies in the range of 1.34-1.39 $\mathrm{m} / \mathrm{s}$ in the absence of separate bicycle paths, whereas the crossing speed of the pedestrian increases significantly if separate bicycle paths are present (1.41-1.54 $\mathrm{m} / \mathrm{s})$. It has been also observed that a similar green phase has been provided for both the pedestrians as well as the cyclists. The pedestrians and cyclists have to cross at the same time, thus increasing the likelihood of pedestrian-cyclist interactions. A separate path provided for cyclists ensures minimal hindrance to the pedestrians on the account of other cyclists crossing the path at the same instance.
The prior discussion elaborates the independent effect of all the significant variables on the crossing speed. No significant correlation has been found in case of cycle length, green time, nature of land use, visibility of crosswalk markings, presence of guard rails, crosswalk surface condition, average pedestrian flow, average traffic speed and average pedestrian crossing time. This may be due to the existence of similarity in the characteristics of the crosswalks or other variables being more significantly correlated.

\section{STEPWISE REGRESSION MODELLING}

The effect of significantly correlated variables on the pedestrian crossing speed at signalised crosswalk locations is modelled with the help of a stepwise linear regression technique. The categorical variables to be included in the model are converted into dummy variables. The categorical variable, classification of road, is converted into two separate dummy variables (Four-lane divided and Six-lane divided). Similarly, for the variable separate bicycle path for the crossing of cyclists, two dummy variables (Semi-operational cycle path and Fully-operational cycle path) have been formed. Before formulating the model, the multi-collinearity diagnostics is run to check the correlation among the selected independent variables. The Variance Inflation Factor (VIF) values less than 10 indicate that high (alarming) multi-collinearity does not exist among the variables (Table 5). However, the variables having values greater than 5 indicate a certain degree of multi-collinearity. Therefore, for modelling, a stepwise regression technique has been employed which could tackle this multi-collinearity issue.

After creating the dummy variables and running the correlation analysis along with the collinearity tests, nine explanatory variables (independent variables) have been recognised at 95 percent confidence interval (crosswalk width, crosswalk length, four-lane 
Table 5 - Multi-collinearity diagnostics of independent variables

\begin{tabular}{||l|c|c||}
\hline \multirow{2}{*}{\multicolumn{1}{c|}{ Model }} & \multicolumn{2}{c||}{ Collinearity statistics } \\
\cline { 2 - 3 } & Tolerance & VIF \\
\hline \hline Crosswalk width [m] & 0.604 & 1.656 \\
\hline Crosswalk length [m] & 0.121 & 8.263 \\
\hline Four-lane divided & 0.156 & 6.410 \\
\hline Six-lane divided & 0.189 & 5.291 \\
\hline Width of pedestrian island [m] & 0.718 & 1.393 \\
\hline Average pedestrian delay [s] & 0.402 & 2.488 \\
\hline Average traffic flow [PCU/hour] & 0.174 & 1.144 \\
\hline Semi-operational cycle path & 0.152 & 6.590 \\
\hline Fully-operational cycle path & 0.116 & 8.629 \\
\hline
\end{tabular}

a. Dependent variable: average ped speed $[\mathrm{m} / \mathrm{s}]$

divided, six-lane divided, width of pedestrian islands, average pedestrian delay, average traffic flow, semi-operational cycle path, fully-operational cycle path) for modelling the pedestrian crossing speed. The model has been developed using the Stepwise Linear Regression (MLR) through SPSS. The estimates of the model along with the standard error, $t$-values, significant values and confidence intervals are summarised in Table 6. The model developed is given in Equation 1.

Pedestrian crossing speed $(\mathrm{Vp})=$

$2.329-0.006(W p)-0.017(D)-0.220(W)$

The model shows that the average pedestrian crossing speed gets vastly influenced by three factors such as crosswalk width, width of pedestrian island and average pedestrian delay. All the three variables have negative unstandardised coefficients revealing the inverse relation between the variables and the crossing speed. The speed of the pedestrians can be easily predicted with the help of these three variables. The model is calibrated using 80 percent data and the remaining 20 percent of data is used for the validation of the model. The calibrated $R^{2}$ value is found as 0.701 which indicates that $70.1 \%$ variation in the predicted crossing speed has been explained by the explanatory variables, or in other words, the regression line. This $R$-square value is higher than the independent $R$-square values found for each variable separately. The graph indicates that the crossing speed model developed through this study yielded results close to the observed values as shown in Figure 4.

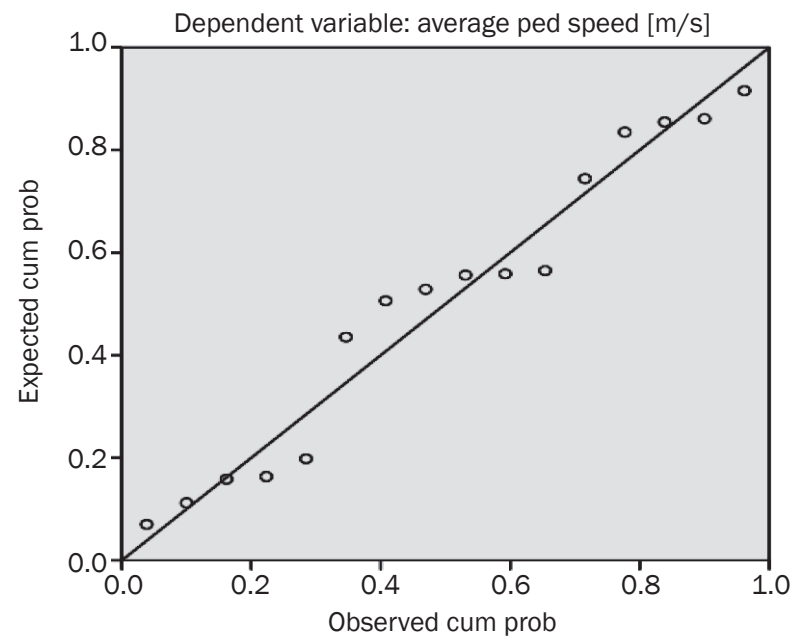

Figure 4 - Comparison between predicted and observed values

Table 6 - Model estimation and calibration results

\begin{tabular}{|c|c|c|c|c|c|c|c|}
\hline \multirow{2}{*}{ Model } & \multicolumn{2}{|c|}{$\begin{array}{l}\text { Unstandardised } \\
\text { coefficients }\end{array}$} & \multirow{2}{*}{$\begin{array}{c}\begin{array}{c}\text { Standardised } \\
\text { coefficients }\end{array} \\
\text { Beta }\end{array}$} & \multirow{2}{*}{$t$} & \multirow{2}{*}{ Sig. } & \multicolumn{2}{|c|}{$\begin{array}{c}\text { 95\% confidence interval } \\
\text { for B }\end{array}$} \\
\hline & B & Std. Error & & & & $\begin{array}{l}\text { Lower } \\
\text { bound }\end{array}$ & $\begin{array}{l}\text { Upper } \\
\text { bound }\end{array}$ \\
\hline (Constant) & 2.329 & .313 & -- & 7.446 & .000 & 1.648 & 3.011 \\
\hline Width of ped island (Wp) & -.006 & .002 & -.485 & -2.963 & .012 & -.011 & -.002 \\
\hline Average pedestrian delay (D) & -.017 & .006 & -.486 & -2.959 & .012 & -.029 & -.004 \\
\hline Crosswalk width (W) & -.220 & .101 & -.347 & -2.183 & .049 & -.440 & .000 \\
\hline
\end{tabular}




\section{DISCUSSION}

A comprehensive literature survey construed that there are significant variations in pedestrian crossing speeds at different crosswalks between the developing countries (India, Thailand, etc.) and the developed countries (USA, UK, etc.). It was also noted that over the course of time, the crossing speed of the pedestrians in the developing countries (especially the Indian cities) have increased tremendously and surpassed the design standard speed limits approved by different manuals. Therefore, the factors influencing the crossing speed were studied and the modelling was carried out to predict the crossing speed at signalised intersections for heterogeneous traffic conditions.

The present study was undertaken at the selected 16 signalised intersection crosswalks in Chandigarh city (India). The $15^{\text {th }}$ percentile speed was found varying between 1.11-1.31 m/s across different study locations. The statistical tests i.e. F-tests exhibited no substantial difference in the percentile speeds for different genders but varied for different age groups and group sizes. The overall $15^{\text {th }}$ percentile speeds found for different genders across the studied crosswalk locations (68 percent) were much higher than the prescribed standard value of $1.2 \mathrm{~m} / \mathrm{s}$. It was also observed that the crossing speed decreases with an increase in age and group size. The pedestrians exhibiting different crossing patterns also affect the crossing speed. One-stage crossing speed was higher as compared to the two-stage crossing. Moreover, the pedestrians carrying baggage or using mobile phones had a significant effect on the crossing speed. The crossing time gets increased and the speed gets decreased if the pedestrian is carrying luggage. Based on other significant influencing factors (geometric, operational and flow characteristics) the correlation analysis found that the factors like crosswalk width, crosswalk length, width of pedestrian island, classification of road, average traffic flow and average pedestrian delay had negative correlation with the crossing speed, whereas separate bicycle path for crossing positively correlated with the crossing speed. The $15^{\text {th }}$ and $85^{\text {th }}$ percentile speeds were found to have higher values for the fourlane divided carriageways in comparison to the six-lane divided carriageways $(1.24 \mathrm{~m} / \mathrm{s}$ vs. $1.21 \mathrm{~m} / \mathrm{s}$ and 1.73 m/s vs. $1.7 \mathrm{~m} / \mathrm{s}$, respectively). Reducing the number of lanes resulted in fewer interferences to the pedestrians, hence shorter crossing time and higher crossing speed. The crossing speed was found to increase till the traffic flow is less than $<2,750 \mathrm{PCU} /$ hour, but with further increase in the traffic flow, the crossing speed is reduced and showed a declining trend. The crosswalk locations with separate bicycle paths recorded higher pedestrian crossing speed (1.41-1.54 $\mathrm{m} / \mathrm{s}$ ) than the locations with no separate bicycle path (1.34-1.39 m/s).
Further, the pedestrian crossing speed was modelled using the stepwise regression technique. The model concluded that only three factors i.e. crosswalk width, width of pedestrian islands and average pedestrian delay contribute a lot in predicting the crossing speed. The coefficient of determination ( $R$-square) was found to be 0.701 indicating 70.1 percent accurate prediction rate.

\section{CONCLUSION}

The present study concludes that the pedestrian crossing speed at signalised intersections has tremendously increased over the past decade due to the improvement in infrastructure, thus demanding the need for revising the prescribed speed limits. Pedestrian characteristics, Traffic factors, Geometric conditions and Operability characteristics exhibit significant effect on the crossing speed. Therefore, it has been suggested to incorporate all the factors while deciding on the pedestrian design crossing speed at signalised crosswalks. The model formulated in this paper should also be applicable to other countries of Southeast Asia where similar traffic conditions prevail.

\section{REFERENCES}

[1] Tiwari G, Bangdiwala S, Saraswat A, Gaurav, S. Survival Analysis: Pedestrian Risk Exposure at Signalized Intersections. Transportation Research Part F: Traffic Psychology and Behaviour. 2007;10: 77-89. Available from: doi:10.1016/j.trf.2006.06.002

[2] Mohan D, Tiwari G, Bhalla K. Road Safety in India. Transportation Research and Injury Prevention Programme (TRIPP), New Delhi, India; 2015. Available from: https://www.worldcat.org/title/road-safety-in-india-status-report/oclc/934705592

[3] Dewar RE. Driver and pedestrian characteristics. In: J. Pline, ed. Traffic engineering handbook. $4^{\text {th }}$ Ed. Englewood Cliffs, New Jersey: Prentice Hall; 1992.

[4] Transportation Research Board. Highway capacity manual. National Research Council, Washington, D.C. Special Rep. No. 209, 2000. Available from: http:// www.trb.org/Publications/Blurbs/153893.aspx

[5] FHWA. Manual on Uniform Traffic Control Devices (MUTCD). Washington, D.C.: Federal Highway Administration; 1988. Available from: https://mutcd.fhwa.dot.gov/

[6] IRC (Indian Road Congress): 103. Guidelines for Pedestrian Facilities. New Delhi, India; 1988.

[7] Holland C, Hill R. The effect of age, gender and driver status on pedestrians' intentions to cross the road in risky situations. Accident Analysis \& Prevention. 2007;39(2): 224-237. Available from: doi:10.1016/ j.aap.2006.07.003

[8] Guerrier JH, Jolibois JSC. The safety of elderly pedestrians at five urban intersections in Miami. Proc., HFES $42^{\text {nd }}$ Annual Meeting, Human Factors and Ergonomics Society, Santa Monica, CA; 1998. p. 35-42.

[9] Peters D, Kim L, Zaman R, Haas G, Cheng J, Ahmed S. Pedestrian Crossing Behavior at Signalized Intersections in New York City. Transportation Research Record: 
Journal of Transportation Research Board. 2015;2519: 179-188. Available from: doi:10.3141/2519-20

[10] Xie SQ, Wong SC, Nga TM, Lam HK. Pedestrian Crossing Behavior at Signalized Crosswalks. Journal of Transportation Engineering Part A: Systems. 2017;143(8): 17-26. Available from: doi:10.1061/JTEPBS.0000055

[11] Lam WHK, Cheung, CY. Pedestrian speed/flow relationships for walking facilities in Hong Kong. Journal of Transportation Engineering Part A: Systems. 2000;126: 343-349. Available from: doi:10.1061/ (ASCE)0733-947X(2000)126:4(343)

[12] Goh BH, Subramaniam K, Wai YT, Ali A. Pedestrian Crossing Speed: The Case of Malaysia. International Journal of Traffic and Transportation Engineering. 2012;2: 323-332. Available from: doi:10.7708/ ij_e.2012.2(4).03

[13] Griffiths JD, Hunt JG, Marlow M. Delays at Pedestrian Crossings: Site Observation and the Interpretation of Data. Traffic Engineering \& Control. 1984;25: 365-371. Available from: http://worldcat.org/issn/00410683

[14] Sjostedt L. Behaviour of pedestrians at pedestrian crossings. Stockholm, Sweden: National Swedish Road Research Institute; 1967.

[15] Cresswell C, Griffiths JD, Hunt JG. Site evaluation of a pelican crossing simulation model. Traffic Engineering \& Control. 1978;19: 546-549.

[16] Wilson DG, Grayson GB. Age-Related Differences in the Road Crossing Behavior of Adult Pedestrians. Transport Research Laboratory, TRB, NCHRP, Washington, D.C. Report No. LR 933, 1980. Available from: https://trid.trb.org/view/168876

[17] Knoblauch RL, Pietrucha MT, Nitzburg M. Field Studies of Pedestrian Walking Speed and Start-Up Time. Transportation Research Record: Journal of Transportation Research Board. 1996;1538: 27-38. Available from: doi:10.3141/1538-04

[18] Fitzpatrick K, Brewer MA, Turner S. Another look at pedestrian walking speed. Transportation Research Record: Journal of Transportation Research Board. 2006;1981: 21-29. Available from: doi:10.3141/1982-05

[19] Gates TJ, Noyce DA, Bill AR, Van ER. Recommended walking speeds for pedestrian clearance timing based on pedestrian characteristics. Transportation Research Record: Journal of Transportation Research Board. 2006;1982: 38-47. Available from: doi:10.1177/0361198106198200106

[20] Bowman BL, Vecellio RL. Pedestrian Walking Speeds and Conflicts at Urban Median Locations. Transportation Research Record: Journal of Transportation Research Board. 1994;1438: 67-76. Available from: http://worldcat.org/isbn/0309055199

[21] Daamen W, Hoogendorn, SP. Pedestrian free speed behaviour in crossing flows. Traffic and Granular Flow. 2007;05: 299-304. Available from: https://link.springer.com/chapter/10.1007/978-3-540-47641-2_25

[22] Asaithambi G, Kuttan MO, Chandra S. Pedestrian Road Crossing Behavior Under Mixed Traffic Conditions: A Comparative Study of an Intersection Before and After Implementing Control Measures. Transportation in Developing Economies. 2016;2. Available from: doi:10.1007/s40890-016-0018-5

[23] Marisamynathan S, Vedagiri P. Modeling Pedestrian Delay at Signalized Intersection Crosswalks under
Mixed Traffic Condition. Procedia - Social and Behavioral Sciences. 2016;104(1): 708-717. Available from: doi:10.1016/j.sbspro.2013.11.165

[24] Chandra S, Rastogi R, Das VR, Ilango T. Pedestrian behaviour under varied traffic and spatial conditions. European Transport. 2014;56(1): 52-64.

[25] Tanaboriboon Y, Guyano JA. Analysis of Pedestrian Movement in Bangkok. Transportation Research Record: Journal of Transportation Research Board. 1991;1294: 52-56.

[26] Tarawneh MS. Evaluation of pedestrian speed in Jordan with investigation of some contributing factors. Journal of Safety Research. 2001;32: 229-236. Available from: doi:10.1016/S0022-4375(01)00046-9

[27] Subramanyam B, Prasanna Kumar R. Improving pedestrian facilities in congested urban areas: a case study of Chennai city. IOP Conf. Series: Earth and Environmental Science. 2017; paper no. 80. Available from: doi:10.1088/1755-1315/80/1/012059

[28] DiPietro CM, King LE. Pedestrian gap-acceptance. Highway Research Record: Highway Research Board. 1970;308: 80-91.

[29] Hatfield J, Murphy S. The effects of mobile phone use on pedestrian crossing behaviour at signalized and unsignalized intersections. Accident Analysis \& Prevention. 2007;39: 197-205. Available from: doi:10.1016/ j.aap.2006.07.001

[30] Goh PK, Lam WHK. Pedestrian Flows and Walking Speed: A Problem at Signalized Crosswalks. Institute of Transportation Engineers Journal. 2004;74(1): 28-33. Available from: http://worldcat.org/oclc/614107147

[31] Rastogi R, Chandra S, Vamsheedhar J, Das VR. Parametric Study of Pedestrian Speeds at Midblock Crossings. Journal of Urban Planning \& Development. 2011;137: 381-389. Available from: doi:10.1061/ (ASCE)UP.1943-5444.0000083

[32] Mantecchini L, Paganelli F. Empirical Analysis of Pedestrian Delay Models at Urban Intersections. Contemporary Engineering Services. 2015;8(21): 981-990. Available from: doi:10.12988/ces.2015.57202

[33] Muleya D, Kharbechea M, Alhajyaseena W, Al-Salem M. Pedestrians' Crossing Behavior at Marked Crosswalks on Channelized Right-Turn Lanes at Intersections. Procedia Computer Science. 2017;109: 233-240. Available from: doi:10.1016/j.procs.2017.05.339

[34] Boroujerdian A, Nemati S. Pedestrian Gap Acceptance Logit Model in Unsignalized Crosswalks Conflict Zone. International Journal of Transportation Engineering. 2016:4(2).

[35] Robertson HD, Hummer J, Nelson D. Manual of Traffic Engineering Studies. Washington, D.C.: Institute of Transportation Engineers; 1994.

[36] Transportation Research Board. Highway capacity manual. National Research Council, Washington, D.C. Special Rep. No. 209, 1994. Available from: http:// www.trb.org/Publications/Blurbs/153893.aspx

[37] Li Q, Wang Z, Yang J, Wang J. Pedestrian Delay Estimation at Signalized Intersection in Developing Cities. Transportation Research Part A: Policy and Practice. 2005:39(1): 61-73. Available from: doi:10.1016/ j.tra.2004.11.002

[38] Behbahani H, Gilani VNM, Samet MJ, Salehfard R. Analysis of Crossing Speed of the Pedestrians in 
Marked and Unmarked Crosswalks in the Signalized and Un-Signalized Intersections (Case Study: Rasht city). IOP Conf. Series: Materials Science and Engineering. 2017; paper no. 245.

[39] The Tribune. Pedestrian Deaths Ring Alarm Bells; 2017. Available from: https://www.tribuneindia.com/ news/chandigarh/community/pedestrian-deaths-ringalarm-bells/346580.html

[40] FHWA. Manual on Uniform Traffic Control Devices for Streets and Highways. Washington, D.C.: Federal Highway Administration; 2003. Available from: https:// mutcd.fhwa.dot.gov/ 